\title{
COMPARATIVE ASSESSMENT OF THE GEOTECHNICAL PROPERTIES OF RESIDUAL SOILS IN PARTS OF AWKA AND ABUJA AREAS OF NIGERIA
}

\author{
I. M. Idehai ${ }^{1}$, A. O. Egai $^{2}$ and M. E. Okiotor ${ }^{3}$ \\ 1,2 DePARTMENT OF Geology, UNIVERSITY OF BENIN, BENIN CITY, NIGERIA

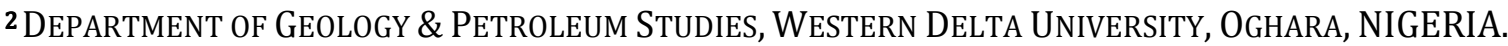 \\ Email addresses: ${ }^{1}$ imoism@gmail.com, 2 aegai19@yahoo.com, ${ }^{3}$ michaelokiotor@gmail.com
}

\begin{abstract}
Residual soil samples from the zone of accumulation were collected from road-cut exposures in Awka (Aks), and Abuja (Abs) within the Nigerian sedimentary and Basement terrains respectively. The soil samples were tested for their geotechnical properties with a view to ascertaining their index and engineering properties in order to determine their suitability for use as construction materials. The liquidity and consistency indices are -0.09 \&-0.49, and 1.09 \& 1.49 for Abs and Aks respectively. Aks and Abs have shear strength (84.84 \& 88.91) $\mathrm{KN} / \mathrm{m}^{2}$, frictional angle; (44 \& 33) , cohesion; ( $0.1 \& 31.65) \mathrm{KN} / \mathrm{m}^{2}$, unconfined compressive strength; (85.89 \& 97.49) $\mathrm{KN} / \mathrm{m}^{2}$, maximum dry density; (18.54 \&15.35) KN/m³ with optimum moisture content of (14.2 \& 22.5)\% and group indices of (0.022 \& 9.54) respectively. Overall, with adequate drainages, Abs will make a better subgrade in flexible pavement design whereas Aks will be better suited for use in slopes and embankments.
\end{abstract}

Keywords: cohesion; geotechnical; residual soils; shear strength; subgrade.

\section{INTRODUCTION}

Soils are often produced by mechanical and chemical weathering of rocks. The products of decomposition either remain in-situ or are transported. The weathering of the underlying bedrock forms residual soils. Residual soils are therefore chemically similar to that bedrock and may contain organic material derived from plants and animals living in the area. The essence of this work which centres on empirical analyses is to study comparatively, the index and engineering properties of in-situ soils developed from two different parent rocks in different parts of Nigeria; Awka in the Campanian- Maestrichtian Sedimentary Anambra Basin, and Abuja in the Precambrian Basement Complex.

The significance of geotechnical tests on soils cannot be over emphasized considering its immense relevance to construction purposes. Designing structures on a soil material without prior knowledge of its engineering behaviour and competence based on geotechnical tests may prove costly in terms of capital, labour, and human misery in the event of failure

\section{LOCATION AND GEOLOGY OF THE STUDY AREAS}

The sample from Abuja was collected in latitude $9.1335^{\circ} \mathrm{N}$ and longitude $7.22288^{\circ} \mathrm{E}$ along Daura Road in the Kubwa area of the FCT (Figure 1). It is a residual soil formed from Zuma rock. The Zuma rock is an igneous intrusion composed of gabbro and granodiorite. The soil colour is dark brown. It is coarse and very plastic with angular grains, some containing quartz and incompletely weathered feldspars

The Awka sample was collected in a location a few metres away from the Enugu-Agidi Road with geographical co-ordinates of latitude $6.2333^{\circ} \mathrm{N}$ and longitude $7.01667^{\circ} \mathrm{E}$ in Anambra State. The geology of Awka is that of the Imo Shale Group. It is overlain by the Bendel Ameki Group and is underlain by crossbedded sandstones and upper coal measures of the Nsukka Formation and Ajali Sandstone. This Formation belongs to the sedimentary Anambra Basin (Figure 2). The sampled soil is a dark brownish red soil with a plastic and gritty feel. Grain fragments are angular. Some metres away from the samples site were thin to thick strata of highly indurated and ferruginised sandstone.

\section{FIELD PROCEDURES AND METHODOLOGY}

A quick reconnaissance study of the sample area was made on reaching the field. The soil profile and characteristics were observed, sketched, and described in a field notebook.

A measure of the plasticity of the soil was obtained by noting how much working on the soil between the fingers was required to dry it; from the wet state, near the liquid limit, to the. crumbling state, near the plastic limit. The greater the plasticity the longer the kneading time required. The zones containing humus were not sampled, since humus impacts weaker 
strength to engineering soil. Ample quantity of representative soil was collected (about $25 \mathrm{~kg}$ per location) for required laboratory test. Some of these were placed in cellophane bags for moisture content determination

A series of tests were conducted on the soil samples. These included natural moisture content determination, Atterberg or consistency limit, free swell linear shrinkage, particle size analysis, determination of the colloidal activities of fine - grained fractions, specific gravity determination, standard compaction, California Bearing Ratio, unconfined compressive strength test and direct shear test.

All the testing procedures were done in line with setstandards. Both the cone penetrometer and casagrande devices were used for the determination of liquid limits. The procedures for the determination of the index and strength parameters were done in accordance with British Standards [2,3].

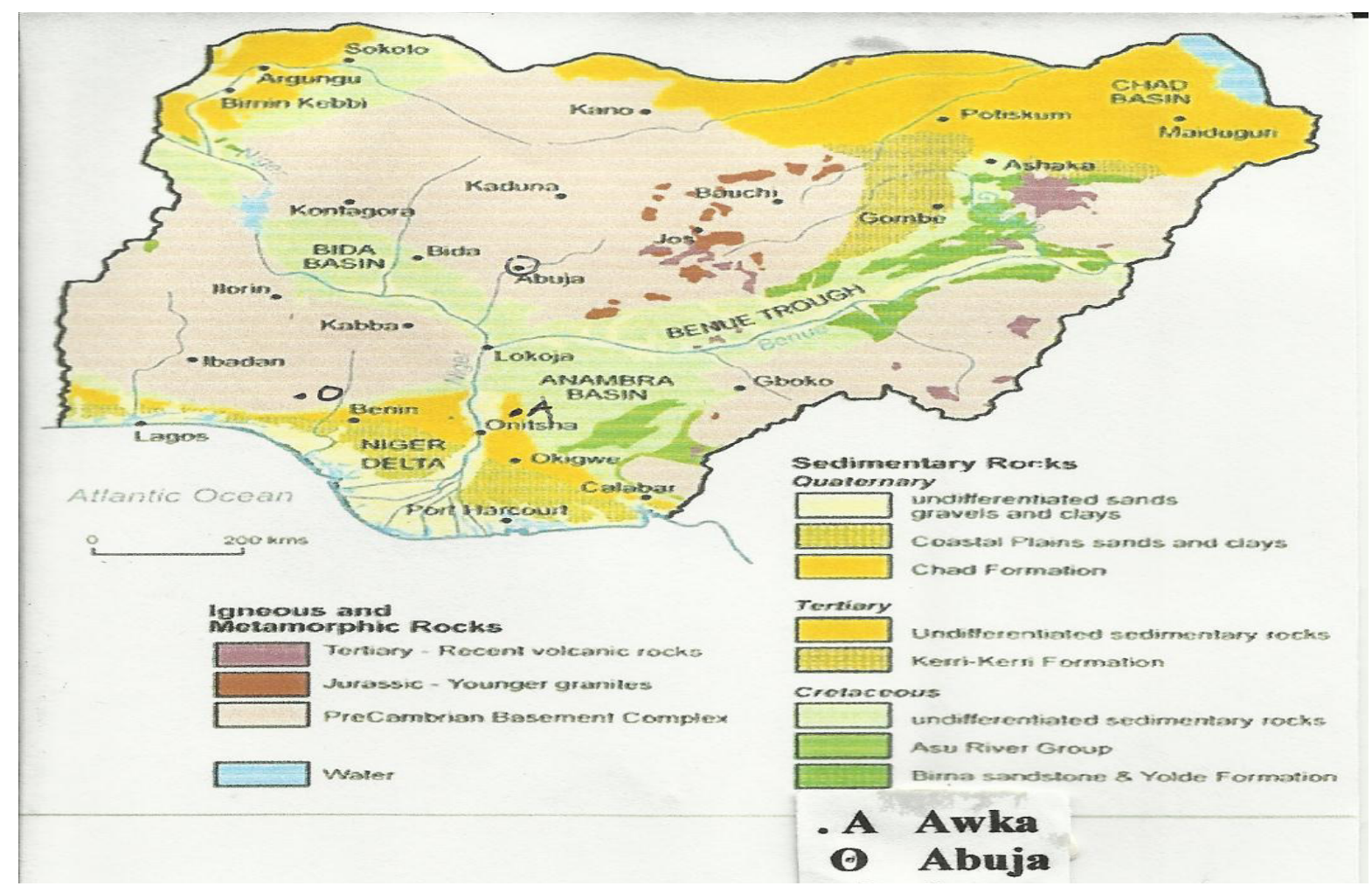

Figure 1: Simplified Geological Map of Nigeria Showing Study Areas.

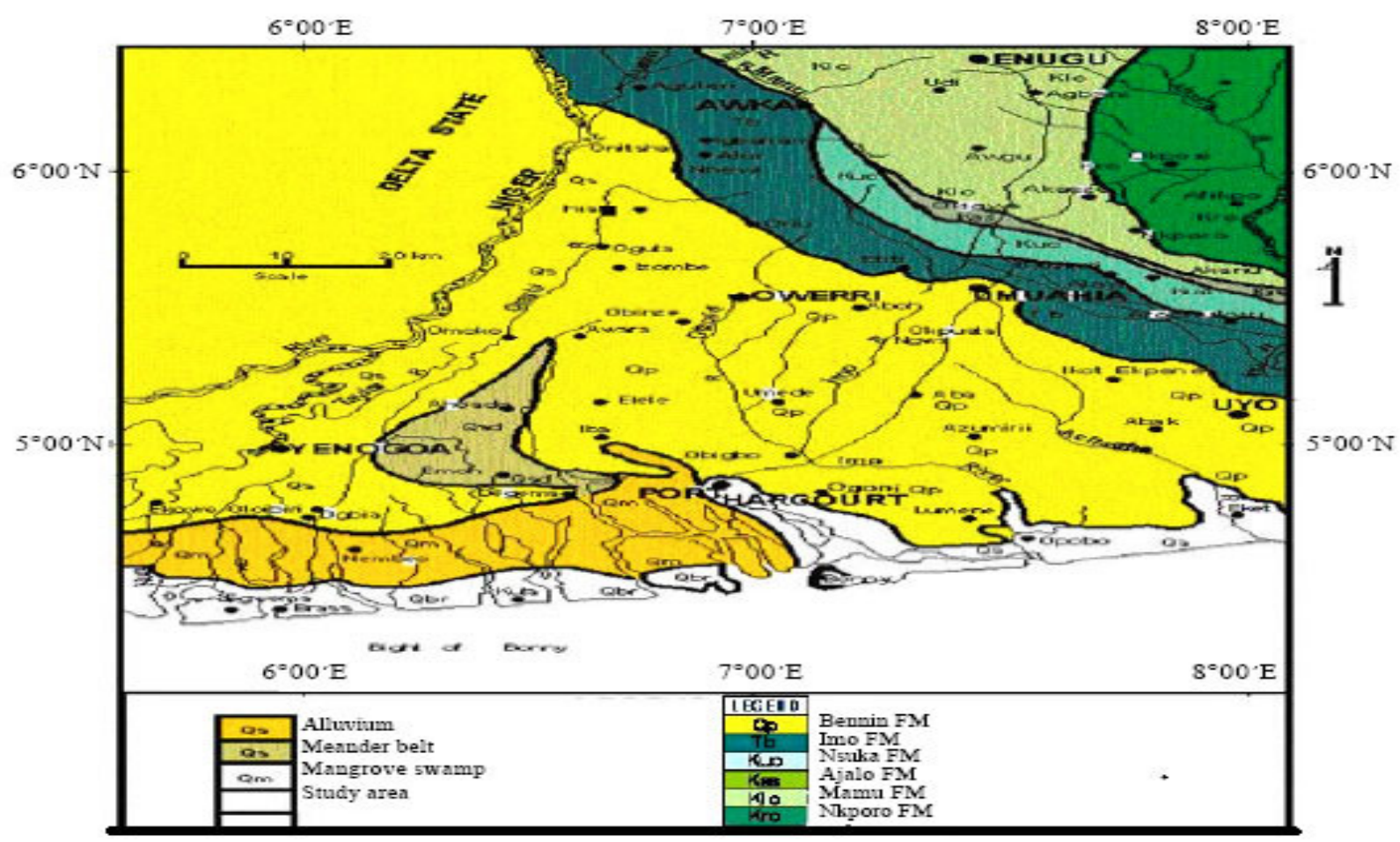

Figure 2: Geological map of Awka and Environs [1] 


\section{RESULTS AND DISCUSSION}

The samples were collected at about the same time during the dry season and the natural moisture content values obtained are consistent with their percentage of fines, the influence of temperature and humidity being almost negligible.

Lower natural moisture content probably reflects lower proportion of fines; therefore, it is not surprising that the Awka soil with lower fines has lower moisture content (Figure 3). Its higher specific gravity of $2.64 \mathrm{~g} / \mathrm{cm}^{3}$ may be attributable to its higher silica and iron content.

The liquid limit (LL) is the lowest water content above which soil behaves like liquid. Normally, this is below 100. This represents the minimum moisture content at which soil will flow under its own weight. Empirical analyses reveal that a disturbed soil at liquid limit has a shear strength around $1 \mathrm{KN} / \mathrm{m}^{2}$ [4]. However, for the present discourse, it is convenient to regard the liquid limit as the water content corresponding to shear strength of about $2.5 \mathrm{KN} / \mathrm{m}^{2}$ [6]. Aks and Abs have LL of ( 40.8 \& 51.7) \% respectively as shown in Figures 4 and 5 .

With reducing moisture content from the liquid limit, the soil becomes stiffer and less plastic and finally emerges into a semi-solid state. The moisture content at which this change occurs is called the plastic limit (PL). The lowest water content at which soil behaves like a plastic material is normally below 40 . Aks and Abs have PL of 21.8 and 20.13 respectively.

Some authors conclude that whatever the structural status of water and the nature of the inter-particle forces, the plastic limit is the lower boundary of the range of water content within which soil exhibits plastic behaviour that is, above the plastic limit, the soil can be deformed without volume change or cracking and will retain its deformed shape $[7,8]$. The plasticity index is derived from the difference between LL \& PL and is an important indicator of the surface chemical activity of the fine soil fraction of the material. It refers to the soil itself and is the change in water content required to increase the strength of disturbed samples a hundred times [4].

Abs with about $27 \%$ of clays and $10 \%$ of silt has a higher PI value of $31.57 \%$ and is more plastic compared with Aks with 23\% clays, 5\% silt and PI of $19 \%$. Collected from a locale close to ferruginised sandstone, it supports claims by other writers that iron oxide coating and cementation of clay mineral leads to a reduction of plasticity characteristics by suppressing the surface activity of the clay fraction.

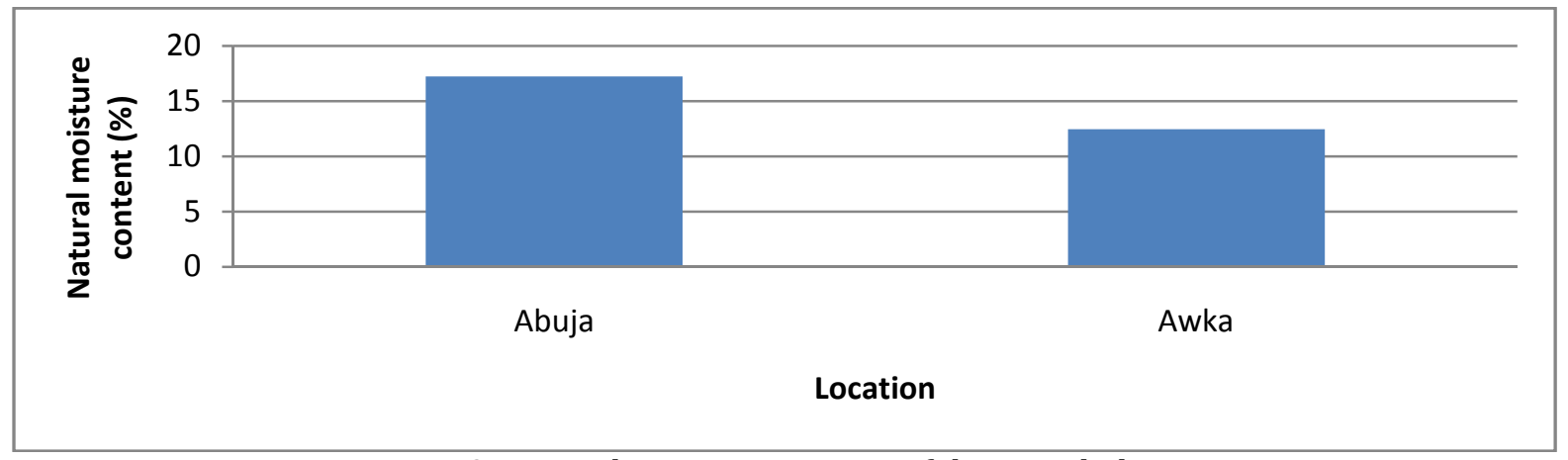

Figure 3: Natural moisture content of the sampled areas.

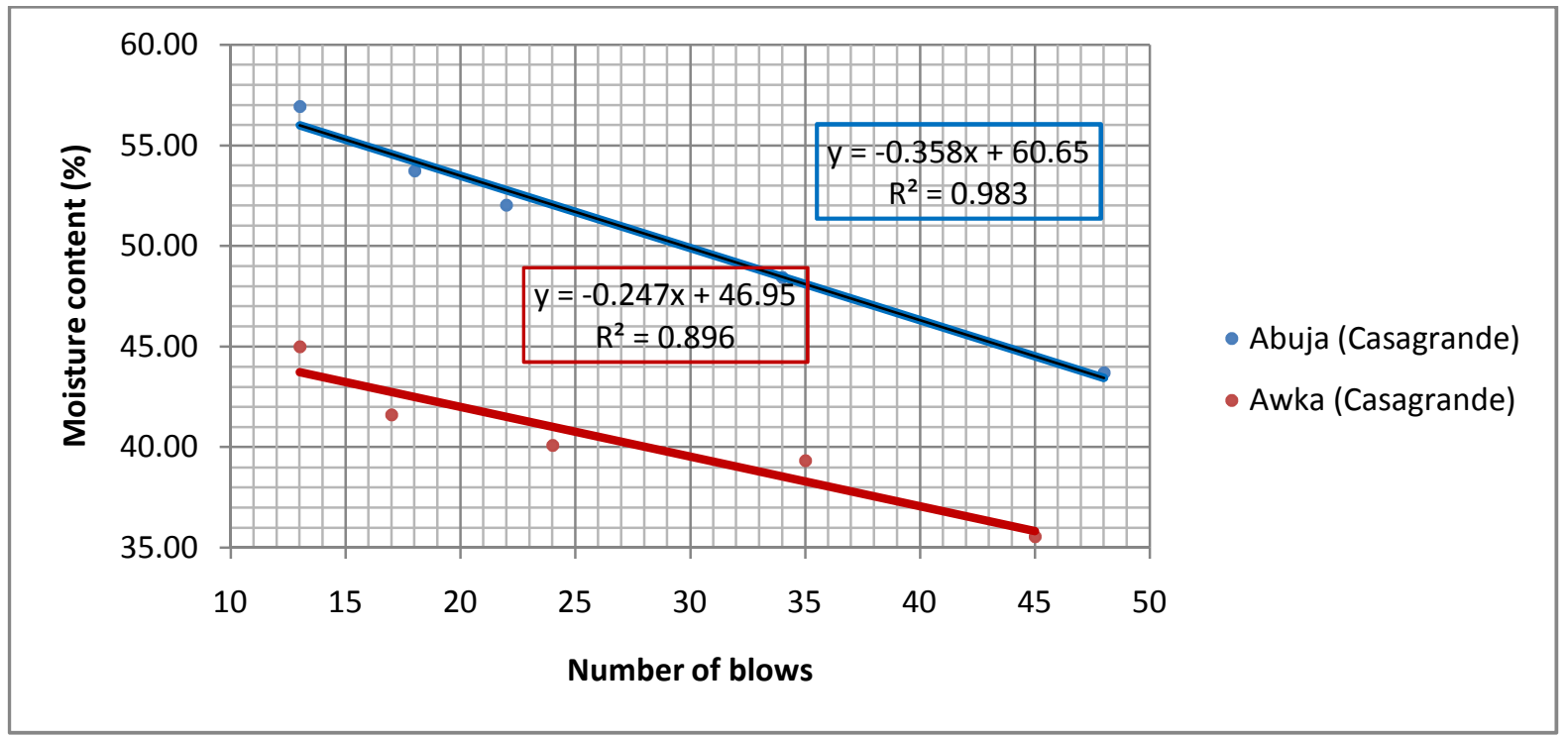

Figure 4: Determination of LL in the sampled areas using the Casagrande device 


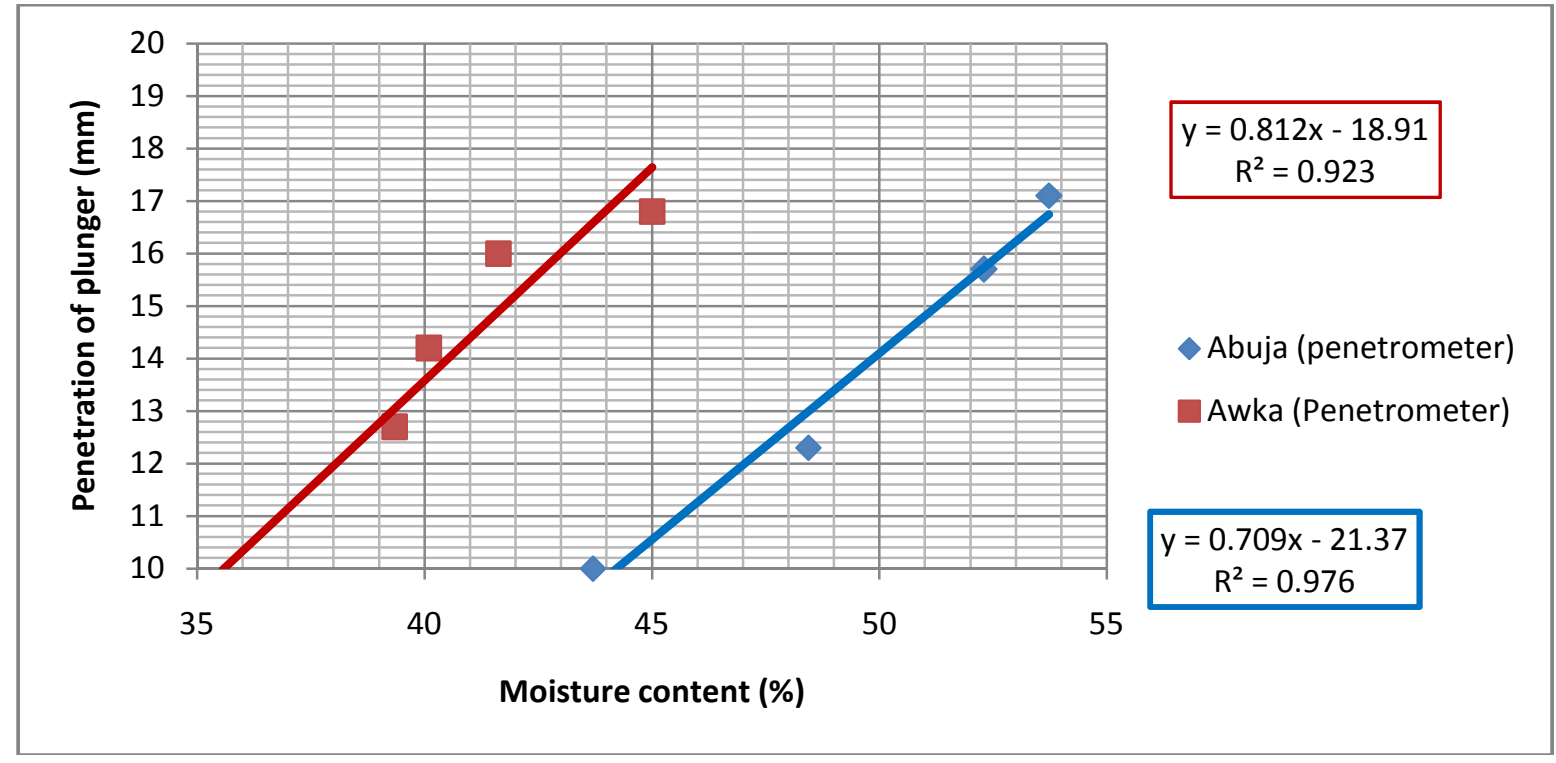

Figure 5: Determination of LL in the sampled areas using the cone penetrometer

A measure of consistency and strength is deduced from the liquidity index LI. LI is given by (w-PL)/PI. The LI values for Aks and Abs are $-0.49 \&-0.09$ respectively, and indicate that both soils are semisolid to stiff since $\mathrm{LI}<0$. A collaborative measure is also inferred from the consistency index $\mathrm{CI}$ (which is derived from (LL-w)/PI).The CI values are 1.49 and 1.09 in the aforementioned order. Similarly, because $\mathrm{CI}$ is $>1$, it buttresses the previous deduction. Also their colloidal activity values of $0.83 \& 1.17$ infers that the clays are normal clays since these values are lower than the $>1.25$ designated for chemically reactive clays. Aks has an excellent soil group index (GI) with a value of 0.022 whereas that of $\mathrm{Abs}^{\prime}$ is fair at 9.54. In general, the rating for a pavement subgrade is inversely proportional to the group index, GI. The higher the soil group index, the poorer the soil as a subgrade material. Granular soil is generally preferred for high-way and embankment material [9]. The closer the soil GI is to zero or negative values, the better it is in terms of its suitability for use as subgrade. The compressibilities of the sampled clays according to Terzaghi \& Peck [10], and then according to NAVFAC [11] are $0.28 \& 0.38$; and 0.25 and 0.41 for Aks \& Abs respectively.

Swelling may cause building foundation to heave to such an extent that building are damaged. However, given their marginal free swell values of $18 \%$ and $22.5 \%$ for the Akwa and Abuja clays respectively, none of the tested soil exhibited such critical swelling since soils with a free swell value below $50 \%$ will not have appreciable volume change when loaded $[6,12]$. The Awka soil clay mineral could be that of illite/kaolinite from shales, limestone or siltstone present in the Anambra Basin from where the sample was collected. The clay mineral in the Abuja soil could be kaolinite from the weathering of feldspars in the Basement Complex. It is known that it is the clay fraction in a soil that will respond to swelling and shrinkage because they are expandable and compressible. The silt and sand fraction are predominantly made up of quartz, which are physico-chemically inert.

Awka and Abuja Soils both plot above the 'A' line of the Casagrande plasticity chart (Figure 6). The clays in Aks are inorganic clays of low plasticity whereas Abs has clays of high plasticity. The soils collected from the Basement Complex area have higher fines (37\%) than that collected from the sedimentary Anambra Basin (28\%). Corollary, Awka has higher percentage of granular materials $72 \%$ than Abs with $63 \%$ granular content.

The purpose of the laboratory compaction test in this work was to determine the proper amount of mixing water to use when compacting the soil in the field and the resulting degree of denseness which can be expected from compaction at this moisture content. Compaction is the process by which the bulk density of an aggregate of matter is increased by driving out air. For any soil, for a given amount of compactive effort, the density obtained depends on the moisture content. At very high moisture contents, the maximum dry density is achieved when the soil is compacted to nearly saturation, where (almost) all the air is driven out. At low moisture contents, the soil particles interfere with each other; addition of some moisture will allow greater bulk densities, with a peak density where this effect begins to be counteracted by the saturation of the soil. The bulk density or dry density of soils is not a constant value, it could be changed in relation with the moisture content of soils and the compaction effort (Figure 7).

From Figures 7 and 8, it is easy to discern that as compaction commences, the dry density increases whereas the void ratio reduces as air is expelled. Similarly, there is an inverse relationship between bulk density and porosity. The optimum water content is the water content that results in the greatest density for a specified compactive effort. 


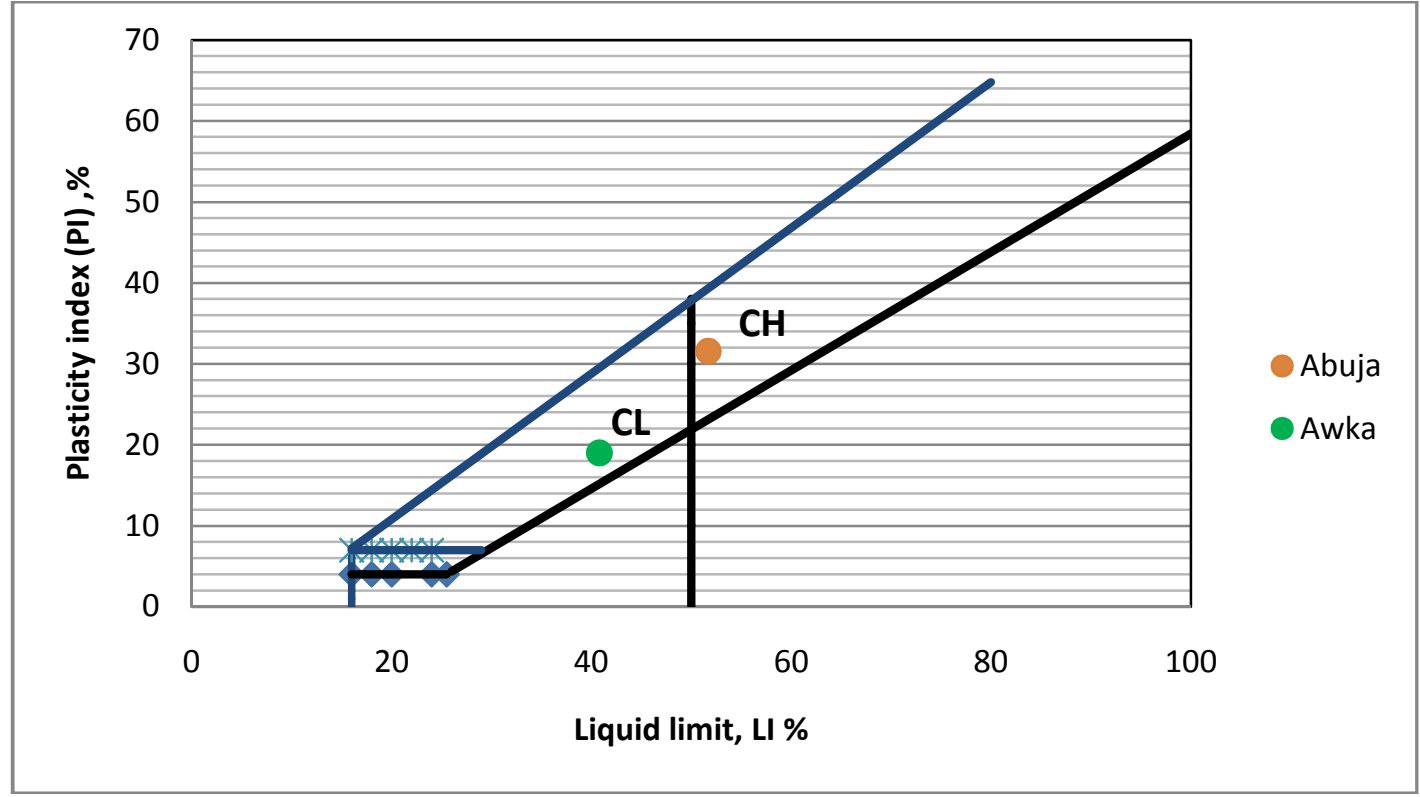

Figure 6: Classification of the sampled soils based on index properties.

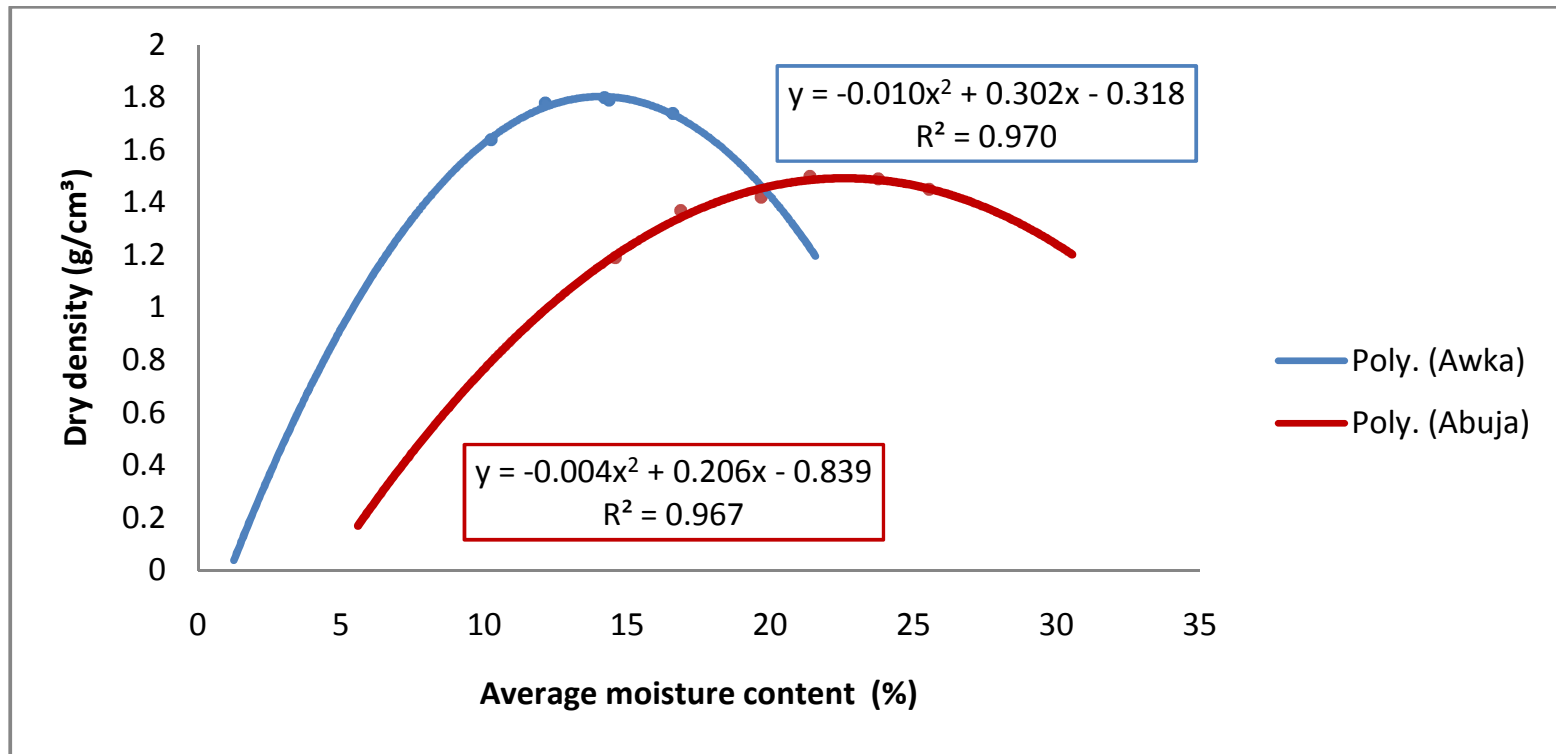

\section{Figure 7: Determination of maximum dry densities and optimum moisture contents}

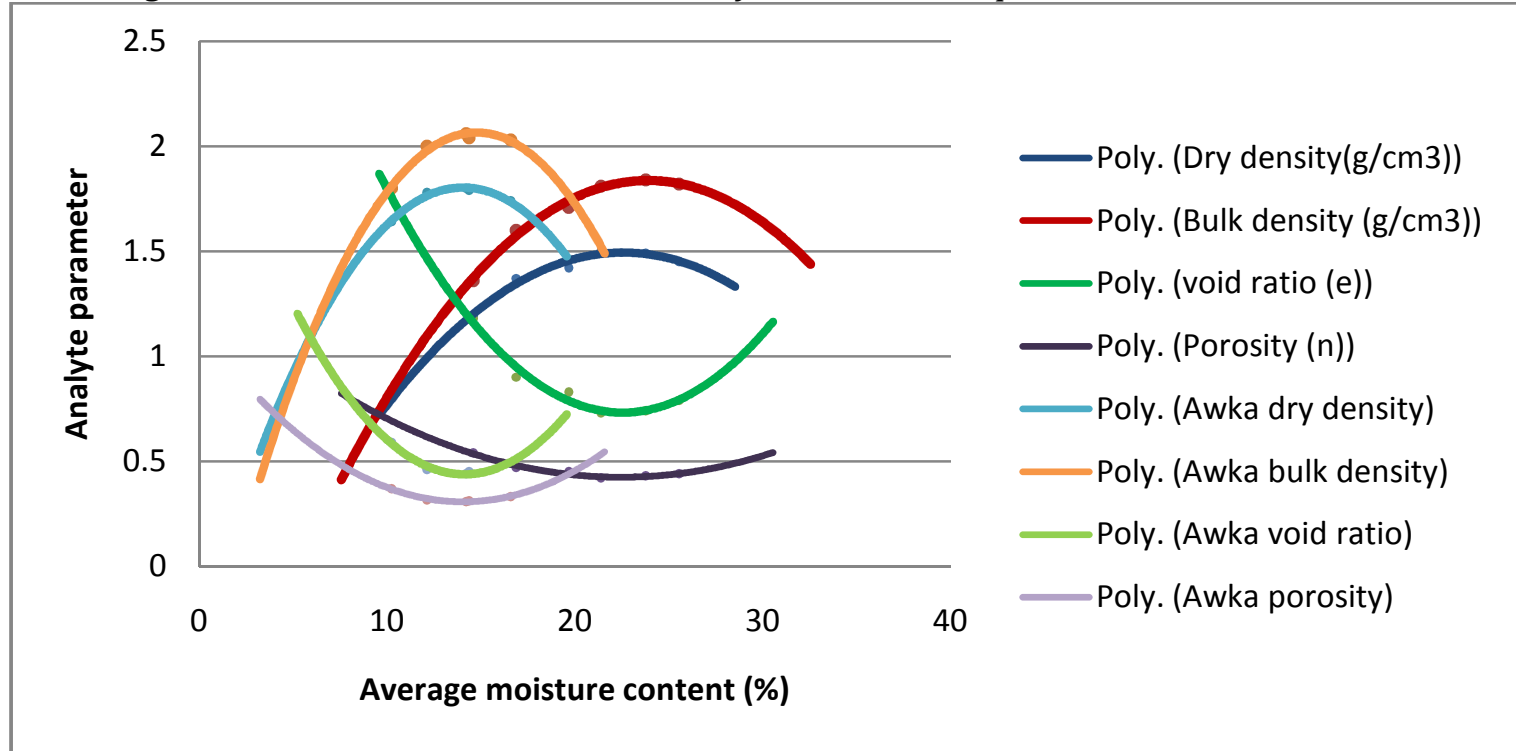

Figure 8: Determination of various compaction indices and ratios. 
Compaction at water contents higher than the optimum water content results in a relatively dispersed soil structure (parallel particle orientations) that is weaker, more ductile, less pervious, softer, more susceptible to shrinking, and less susceptible to swelling than soil compacted dry of optimum to the same density. The soil compacted lower than (dry of) the optimum water content typically results in a flocculated soil structure (random particle orientations) that has the opposite characteristics of the soil compacted wet of the optimum water content to the same density. Knowledge of density is essential in all problems where the body of the strata is an important factor, e.g. stability of slopes of earth dams; earth pressure on retaining walls, tunnel linings and timbering of excavation. The method of designing inverted fillers for dams, levees etc. uses the particles size distribution of the soils involved. This method is based on the relationship of grain size to permeability, along with experimental data on the grain size distribution required to prevent the migration of particles when water flows through the soil.

Shear strength is a term used in soil mechanics to describe the magnitude of the shear stress that a soil can sustain. The shear resistance of soil is a result of friction and interlocking of particles, and possibly cementation or bonding at particle contacts. Due to interlocking, particulate material may expand or contract in volume as it is subject to shear strains. If soil expands its volume, the density of particles will decrease and the strength will decrease; in this case, the peak strength would be followed by a reduction of shear stress. The stress-strain relationship levels off when the material stops expanding or contracting, and when interparticle bonds are broken. The volume change behavior and interparticle friction depend on the density of the particles, the intergranular contact forces, and to a somewhat lesser extent, other factors such as the rate of shearing and the direction of the shear stress. The average normal intergranular contact force per unit area is called the effective stress.

From the shear strength results, it is obvious that the stress-strain relationship of soils, and therefore the shearing strength, is affected by many factors. They include: the soil composition (mineralogy, grain size and grain size distribution, shape of particles, pore fluid type and content, ions on grain and in pore fluid.); initial state (defined by the initial void ratio, effective normal stress and shear stress (stress history)) ;structure (arrangement of particles within the soil mass; cementation, etc) [6].

A granular soil has no shearing resistance at a free surface but it increases fairly rapidly with increase of depth because of the appreciable internal friction. Since the shearing strength of cohesive soil is usually derived almost entirely from the cohesive strength, and very little or none from internal friction, the strength of a cohesive soil of constant water content increases very, little with the increase of depth $[7,14]$. Using the Tresca criterium, both soils are stiff soils because the undrained shear strength of Aks and Abs of $(84.48 \& 88.91) \mathrm{KN} / \mathrm{m}^{2}$ respectively are between $75-150 \mathrm{KN} / \mathrm{m}^{2}$.

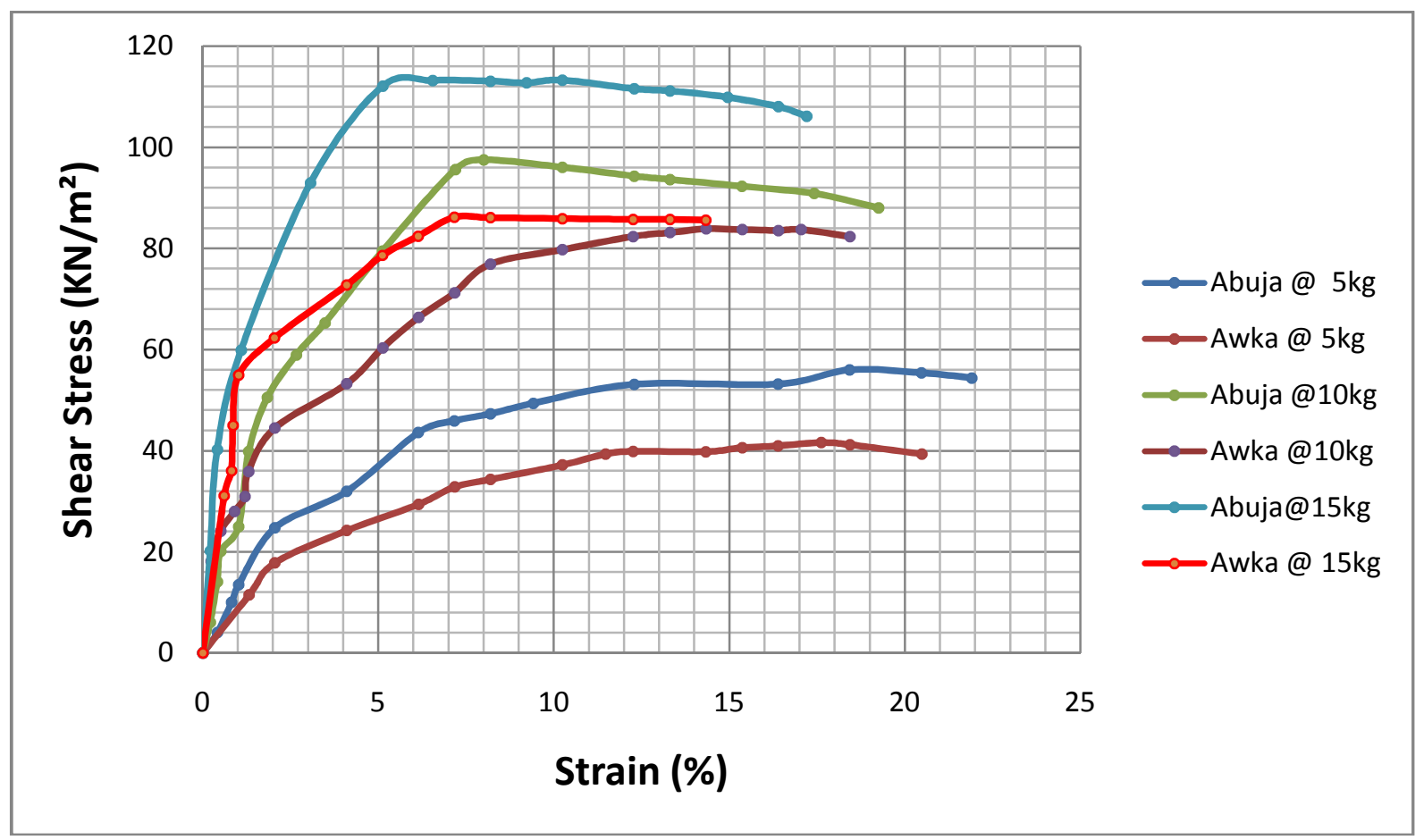

Figure 9: Determination of unconfined compressive strength in the sampled soils. 


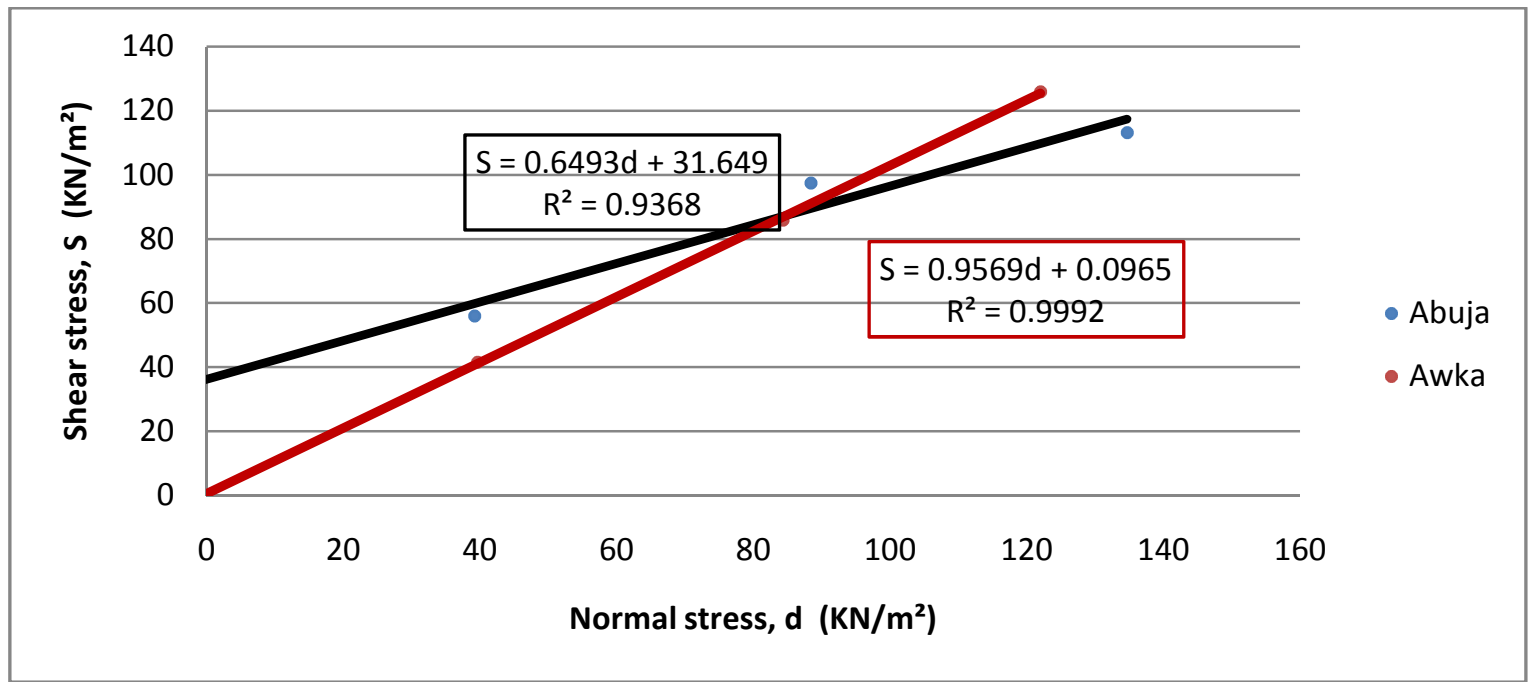

Figure10: Determination of shear strength and angle of friction using direct shear test

When a load is applied to a confined mass of soil, failure will eventually occur when the individual soil grains begin to move relative to each other, i.e. when sliding or shearing will take place along a shear plane. When this "plastic" state of stress is reached the soil mass will be unable to support any additional load. The strength of a soil is therefore dependent on its shearing resistance. The Awka soil (Aks) has a negligible cohesion $\left(0.1 \mathrm{KN} / \mathrm{m}^{2}\right)$ resulting from it having the lowest percentage of fines. Correspondingly, it has the highest internal friction angle of $44^{\circ}$. This is plausibly due to its having a higher percentage of granular materials. It may be instructive to note that further studies in the inherent clay type in this soil may be required given its relative lower plasticity with yet seeming anomalous response to soaking during the CBR test. The purpose of compacting the disturbed samples used for this test was to improve the strength and durability of the soil. Soaking was done to stimulate highly unfavourable moisture condition of the prototype soil. The problem of whether or not to soak the samples for a specific design is one of the most controversial features of the CBR design procedures. Studies reported by the Corps of Engineers (U.SA), indicates that moisture accumulated in cohesive soils even in arid climates.

Based on the standard CBR designing curves for roads, Aks with a higher CBR value $(49.97 \%)$ will require a lower pavement thickness than Abs with CBR of $26.79 \%$. Unlike materials like steel, most of the soils are visco-elastic, meaning the failures are time dependant. Higher CBR reading of a soil (> $15 \%$ ) denotes suitability for use as subgrades. With stronger subgrade, the road pavement thickness is reduced thereby saving capital.

However the soaked values indicate that Abs will be better suited for use as a subgrade since Aks will require more workings in terms of drainage in the event of pore pressure build up due to excessive moisture. Experience has shown that the largest percent of pavement failures is due to poor subgrade condition and excessive subgrade deformation. The improvement of subgrade support by good compaction close to the optimum moisture content can be the most economical measure to take for increased load capacity $[14,15]$.

In highway consideration, a dry granular soil makes a more stable embankment and a better foundation and subgrade for a road surface, The unsoaked CBR values attest to the percentage of granular materials contained in each soil. Awka has the highest concentration of granular materials (72\%). It will be better suited for use in slopes and embankment given its relative higher angle of friction. Stability in ground water level will maintain the effective weight of the material that it saturates without increasing pore water pressure. Unfavourable conditions can be checked if effective sub drainage systems are put in place. This will help to reduce maintenance and early replacement problems. Consequently, engineers resort to subdrainage whenever needed to assure maximum service and long life of the embankment or pavement with minimum maintenance and disruption of traffic. For example, unstable soils require the most efficient drainage for railway, municipal and airport application. Also the use of perforated steel pipe subdrains for the upstream side of levees and the downstream slope of earth and rock dams is considered good engineering practice. The purpose it to relieve the groundwater pressure of accumulating seepage.

Subgrade performance is a function of a soil's strength and its behaviour under traffic loading. The subgrade should be sufficiently stable to prevent excessive rutting and shoving during construction, provide good support for placement and compaction of pavement layers, limit pavement rebound deflections to acceptable limits, restrict the development of excessive permanent deformation (rutting) in the subgrade during the service life of the pavement and minimise effect of changes in moisture level. 

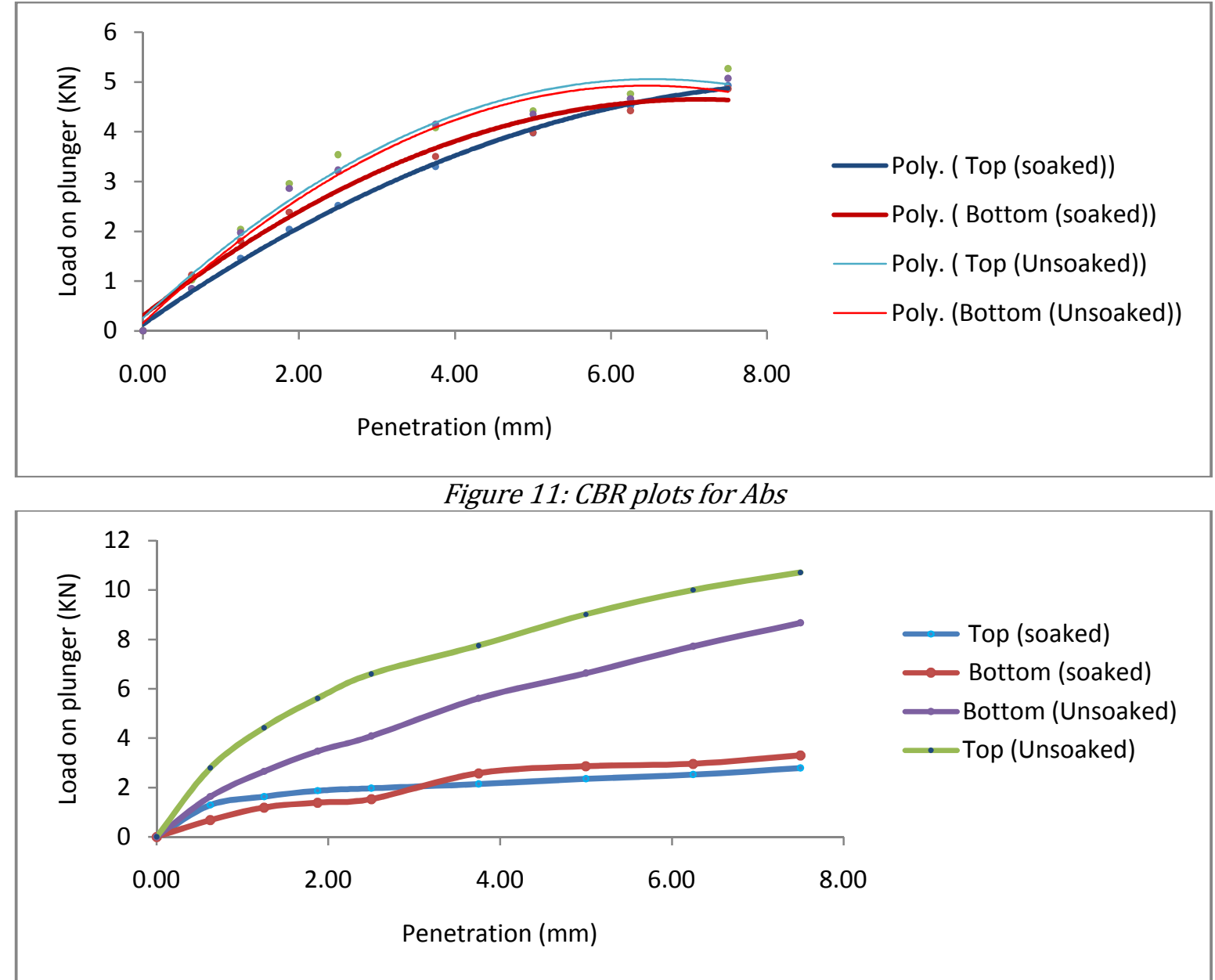

Figure12: CBR plots for Aks

\section{CONCLUSION}

The soils tested are admixtures of fine and granular materials. Their geotechnical properties reflect the combined effects of these fractions with moisture. Compaction of the soils will increase their densities upon the expulsion of air, and increase their strength parameters. Results of simulation of the soils to unfavourable conditions show that their suitability for engineering purposes will greatly be enhanced by efficient and effective drainage. Overall, both soils qualify for use in common construction works requiring the use of soils. Abs may be better suited for use as a subgrade in flexible pavement designs whereas Aks seems more pliable for use in slopes and embankments.

\section{ACKNOWLEDGEMENT}

The authors are grateful for the immense support and assistance enjoyed from Engr. J. A Imouokhome (former Director, Edo State Ministry of Works), Dr. T. U.S. Onyeobi and the chief technicians of the Geology, and Civil Engineering laboratories, University of Benin.

\section{REFERENCES}

[1] Ehirim, C.N. and. Ebeniro, J.O. Evaluation of Aquifer Characteristics and Ground Water Potentials in Awka, South East Nigeria, Using Vertical Electrical Sounding. Asian Journal of Earth Sciences, 2010 3: 73-81.

[2] BS-1377 British Standard Methods of Test for Soils for Civil Engineering Purposes. London, 1990.

[3] BS 5930. Code of Practice for site Investigation. British Standards Institution, London, 1999.

[4] Waltham, T. Foundations of Engineering Geology, Second Edition. London: Taylor \& Francis, 2002.

[5] Poulos, S. J. Liquefaction related phenomena; Advanced Dam Engineering for Design Construction and Rehabilitation Van Nostrand Reinhold (ed.) Jansen R B, 1989. pp. 292-320.

[6] Lee, D.H. Introduction to Deep foundations and Sheet piling, London: Concrete Publications Ltd, 1961. 112-160. 
[7] Mitchell, J. K. Fundamental of Soil Behaviour, Wiley: New York. 1976.

[8] Zhang L. Engineering Properties of Rocks, Oxford: Elsevier. 2005.

[9] Onyelowe, K.C. and Agunwanba, J. C. Geotechnical Examination of the Geophysical Properties of Olokoro Borrow Site Lateritic Soil for Road Works. Nigerian Journal of Technology. Vol.31, No3. 2012. Pp 397- 400.

[10] Terzaghi, K. and Peck, R.B. Soil Mechanics in Engineering Practice. $2^{\text {nd }}$ edition. New York: Wiley 1967.
[11] NAVFAC. Soil Mechanics Design Manual .Naval Facilities Engineering Command, Alexandria, USA. 1992.

[12] Abramson, L.W, Lee T.S, Sharma, S and Boyce . Slope Stability and Stabilization methods. New York: John Wiley and Sons Inc. 1996.

[13] Venkatramaiah C. Geotechnical Engineering, $3^{\text {rd }}$ edition, New Delhi: New Age International Publishers, 2006. 923

[14] Woods K.B., Berry, D.S. and Goetz, W.H. - Highway Engineering Handbook. USA: McGraw-Hill, 1960.

[15] Punmia B.C, and Jain A.K. Soil Mechanics and Foundations, Bangalore: Laxmi Publications Ltd, 2005. 